\title{
OPTIMALISASI PENYUSUTAN EXIF METADATA DENGAN TEKNIK SUBSTITUSI NULL VALUE PADA KASUS KEAMANAN CITRA DIGITAL
}

\author{
Hendro Wijayanto ${ }^{1)}$, Iwan Ady Prabowo ${ }^{2)}$, Paulus Harsadi ${ }^{3)}$ \\ ${ }^{1,2,3)}$ Program Studi Teknik Informatika, STMIK Sinar Nusantara Surakarta \\ ${ }^{1}$ hendro@sinus.ac.id, ${ }^{2}$ iwanadyp@ sinus.ac.id, ${ }^{3)}$ paulus@sinus.ac.id
}

\begin{abstract}
Data and information security technique is a way to keep an object confidential. eXchangable Image File Format (EXIF) Metadata is data information about digital image. In the digital forensic investigation, this is very useful for copyright security or safeguarding digital evidence. Steganography and cryptography techniques have been widely used to overcome these problem. However, from the research that has been done in terms of security EXIF of metadata digital image photography, there are still some weaknesses. Among them is the depreciation of the digital image size after decryption. Since the standard EXIF metadata treatmens released by JEIDA and CIPA have different characteristic with JFIF metadata. A null value will be deemed to be the content with a value of 1 in EXIF standard. While in JFIF metadata model, the value of null is considered to be worth 0 (zero). This is make the EXIF metadata security process is shrinking of $25,15 \%$ from the original size. With the optimizing null value before encryption, the same metadata will be obtained between original image and after decryption. The null value will be replaced with an empty string (it's worth 1) before encryption. Results from the model obtained an average of $-1,51 \%$ depreciation of the original digital image size.Therefore, this technique can optimize the digital image copyright protection.
\end{abstract}

Keywords : substitution, EXIF, optimization, metadata, security, image forensic

\section{PENDAHULUAN}

Citra digital merupakan salah satu jenis barang bukti digital yang memiliki tingkat resiko manipulasi dan kehilangan informasi yang sangat tinggi. Data citra digital (metadata) memiliki informasi yang sangat kompleks, meliputi informasi perangkat pengambilan gambar sampai dengan waktu kapan diambil (Zhou et al., 2016). Sehingga dapat dikatakan metadata citra digital tersebut dapat digunakan sebagai hak cipta. Dalam ranah digital forensik, selain konten citra, metadata dapat digunakan sebagai barang bukti digital di persidangan. Mudahnya manipulasi dari sisi metadata dan konten citra inilah yang menjadi celah untuk melemahkan kedudukan citra digital sebagai alat bukti di persidangan.

Banyak sekali cara untuk mengamankan metadata, mulai dari teknik steganografi, kriptografi sampai dengan watermarking. Kombinasi pengamanan eXchangable Image File Format (EXIF) metadata dengan teknik steganografi dan kriptografi juga telah dilakukan penelitian dengan hasil hampir sempurna dalam mengamankan metadata citra digital. Hal ini disebabkan antara citra digital asli, citra digital setelah dienkripsi, dan citra digital setelah dilakukan dekripsi, memiliki nilai histogram sama, serta dapat mengamankan keseluruhan metadata. Akan tetapi dalam penelitian tersebut, ukuran citra digital mengalami penyusutan sebesar $-25.15 \%$, sehingga hanya dapat digunakan sebagai perlindungan hak cipta citra digital saja. Untuk dapat digunakan sebagai perlindungan barang bukti digital, nilai hashing citra asli dan citra setelah dekripsi harus sama (Wijayanto et al., 2016).

Penyusutan dalam penelitian tersebut dikarenakan perbedaan tipe header metadata citra asli dengan citra setelah dekripsi, yaitu eXchangable Image File Format (EXIF) menjadi JPEG File Interchange Format (JFIF) (Wijayanto et al., 2016). Ini disebabkan 
terjadinya pengolahan citra digital dengan aplikasi. Berdasarkan Japan Electronic Industries Development Association (JEIDA), EXIF berada di dalam segmen APP1 dari citra, sedangkan JFIF berada di segmen APP0 (JEIDA (Japan Electronic Industries Development Association), 2012). Berdasarkan Standard of the Camera \& Imaging Products Assosiation (CIPA), atribut informasi didalam EXIF metadata, memiliki jumlah yang sudah ditentukan. Semua attribut tidak selamanya terisi nilai, tergantung kamera yang digunakan (CIPA (Camera \& Imaging Product Association), 2012).

Dari pemaparan tersebut dapat disimpulkan bahwa pengamanan citra digital untuk keamanan hak cipta masih memiliki kekurangan. Dimana penyusutan ukuran file masih cukup besar, yaitu $-25.15 \%$ dari ukuran aslinya. Dengan melakukan teknik optimalisasi proses enkripsi-dekripsi, diharapkan dapat mengurangi tingkat penyusutan. Jika tingkat penyusutannya mendekati $0 \%$, maka selain sebagai pengamanan hak cipta citra digital juga dapat digunakan sebagai alat bukti di persidangan dan investigasi.

\section{TINJAUAN PUSTAKA}

Citra digital dapat digunakan sebagai alat bukti yang sah di persidangan selama tidak merubah konten gambar dan metadata (Casey, 2011). Metadata merupakan informasi data dari data. Seluruh informasi kamera, waktu pengambilan gambar, serta sistem yang digunakan akan tersimpan didalam metadata dengan tipe EXIF. Informasi didalam EXIF inilah yang merepresentasikan metadata citra digital selain tekstur gambar (Casey, 2011)(McMicken, 2014). Metadata selain dapat digunakan sebagai perlindungan hak cipta citra digital, juga dapat digunakan sebagai alat bukti di persidangan. Karena didalamnya tersimpan semua informasi data citra digital tersebut (Huang \& Fang, 2010).

Didalam proses psengamanan EXIF metadata dengan kombinasi konsep steganografi dan kriptografi di penelitian sebelumnya, EXIF metadata diambil dari citra digital (Citra A) dalam bentuk PlainEXIF, kemudian di enkripsi dengan algoritma tertentu, menghasilkan ChiperEXIF, dan disisipkan di End of File citra digital (Citra A'). Hal ini akan melindungi Metadata citra digital dari penyalahgunaan pihak ketiga. Model algoritma enkripsi tersebut dapat dilihat pada gambar 1

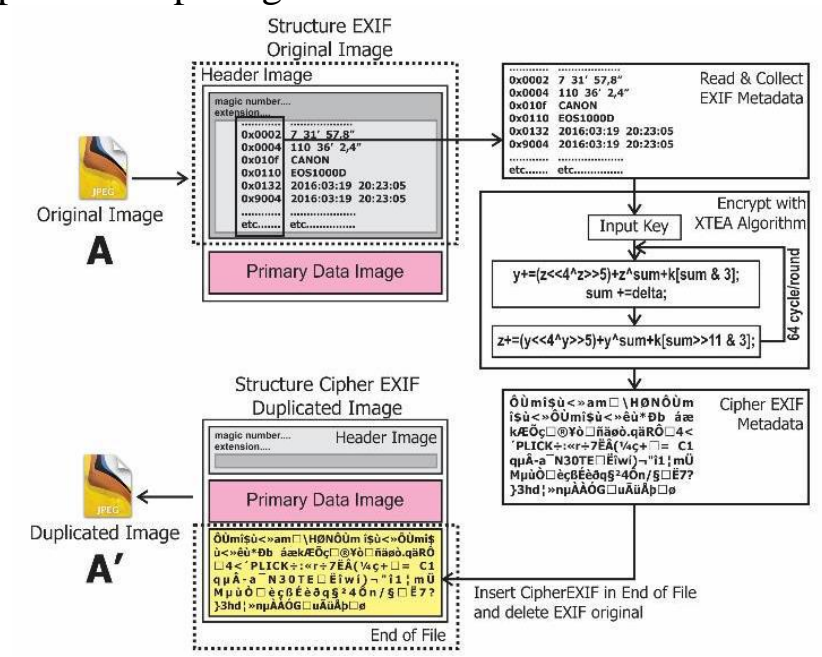

Gambar 1. Model Proses Enkripsi EXIF Metadata (Wijayanto et al., 2016)

Proses pengembalian metadata dilakukan dengan cara mengambil ChiperEXIF untuk di dekripsi menjadi PlainEXIF dan dikembalikan ke header (Citra A'). Sehingga citra A" memiliki EXIF metadata yang sama dengan citra A. Model algoritma dekripsi tersebut dapat dilihat pada gambar 2 (studi kasus menggunakan algoritma XTEA untuk enkripsi, dan End of File untuk steganografi). 


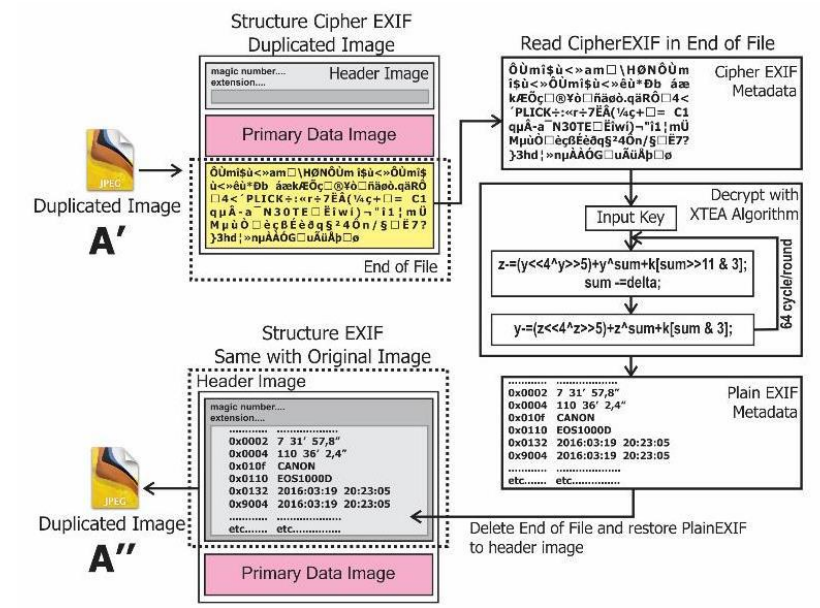

Gambar 2. Model Proses Dekripsi EXIF Metadata (Wijayanto et al., 2016)

Berdasarkan penelitian yang telah dilakukan tersebut, proses enkripsi-dekripsi inilah yang menyebabkan penyusutan pada citra digital setelah dilakukan dekripsi. Adapaun untuk citra histogram, EXIF metadata, komposisi fisik citra (height, width dan pixel) dapat terlindungi.

Dalam proses investigasi citra digital, kelompok metadata yang diperlukan, yaitu (Raghavan \& Raghavan, 2014) :

1. Source, meliputi atribut image file name, location of digital image file, dan editing software.

2. Timestamps, meliputi created date, last modified, last accessed, last saved, date/time original, dan date/time digitized.

3. Ownership, meliputi camera make dan camera model.

4. Application, meliputi content type, image file size, image height, image width, dan image encoding.

Keempat kelompok metadata tersebut berada di header citra digital dengan masing-masing atribut memiliki nilai yang meliputi (CIPA (Camera \& Imaging Product Association), 2012) :

1. Tag Name, nama atribut EXIF metadata.

2. Field Name, nama atribut EXIF metadata yang ditampilkan di detail properties citra digital.

3. Tag ID, identitas unik dari atribut metadata citra digital yang direpresentasikan dalam bentuk decimal dan hexadecimal.

4. Type, tipe data dari value atribut metadata.

5. Count, jumlah jenis atribut yang ekuivalen atau panjang value.

Seluruh informasi EXIF metadata tersimpan di Header citra digital dengan penanda Tag ID. Informasi tersebut tidak berurutan sesuai Tag ID-nya, tetapi tersimpan secara acak di sepanjang header berdasarkan teknologi kamera yang digunakan. Dilihat dari strukturnya, EXIF metadata tersimpan dalam bentuk fragmentasi data (Sencar \& Memon, 2009). Jika dilihat dalam bentuk source, EXIF metadata tidak nampak nilai nyatanya, karena tersimpan dalam bentuk hexadecimal. Agar dapat dibaca nilai yang terkandung didalam EXIF metadata, harus dirubah ke dalam plaintext dengan merujuk tabel EXIF standard. Berikut contoh tabel referensinya : 


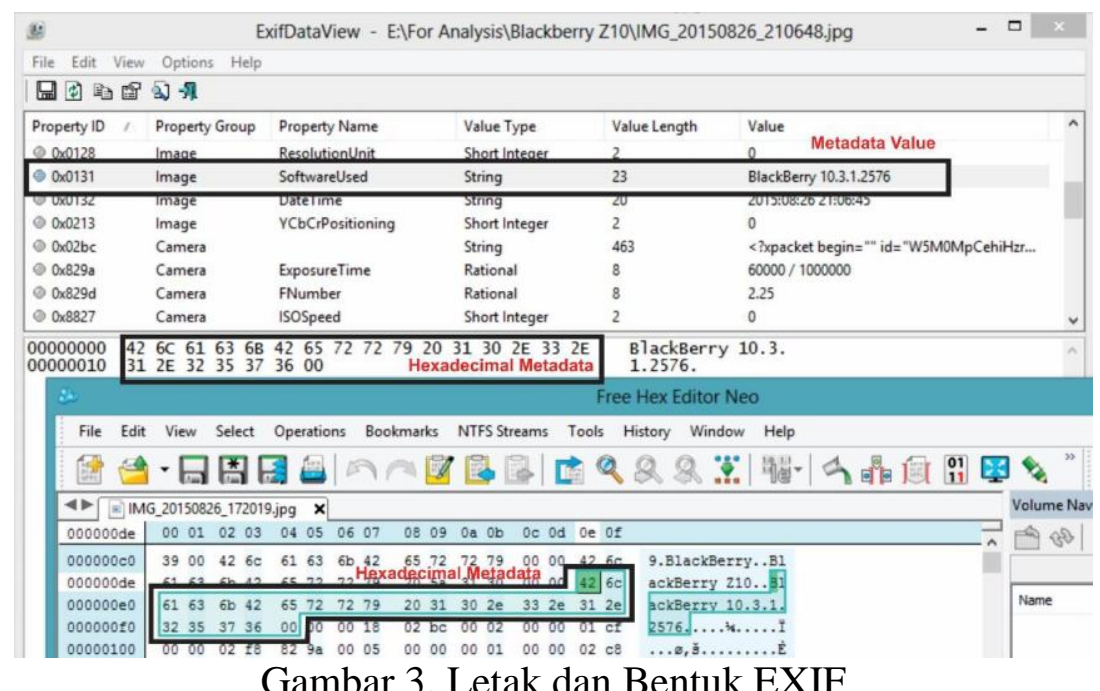

Teknik substitusi dapat digunakan untuk mengganti data informasi yang sensitif. Teknik ini juga sering disebut sebagai Data Masking. Terdapat data atau informasi yang sensitif dan tetap digunakan walau sebenarnya tidak begitu dibutuhkan oleh penerima informasi. Data yang semacam ini sangat penting untuk konsistensi data yang tersimpan. Sehingga walaupun kurang begitu bermanfaat bagi penerima informasi, tetapi sangat penting untuk pertukaran data didalam database. Contohnya untuk menanggulangi inkonsistensi dan kehilangan data (Ltd, 2000).

Teknik substitusi secara acak mengganti kolom data yang telah ditentukan karakteristiknya dengan informasi serupa. Tetapi hal ini sama sekali tidak mempengaruhi informasi asli atau rincian nyata. Sebagai contoh kecil dalam database, pada kolom Nama Karyawan dapat diganti dengan Nama saja. Teknik ini sangat cocok untuk melakukan substitusi Null Value didalam proses pengamanan EXIF Metadata, dimana data kosong (Null) dapat di substitusi dengan String kosong. Sehingga secara komunikasi data informasi, tidak mempengaruhi maksud dari data tersimpan, dan hanya berpengaruh pada panjang data (diperjelas pada Gambar 5).

\section{METODE PENELITIAN}

Dari latar belakang dan landasan teori berdasarkan penelitian terkait sebelumnya, proses pengamanan EXIF metadata dengan menggabungkan teknik kriptografi-steganografi memiliki 4 hal penting, yaitu:

1. Proses pencarian dan penterjemahan EXIF metadata ke dalam bentuk plaintext. Sehingga dapat dibaca nilai valuenya.

2. Proses enkripsi plain EXIF metadata dengan algoritma, dan menyimpannya di dalam End of File citra digital

3. Proses pencarian dan dekripsi chiper EXIF dengan algoritma, dan kemudian diterjemahkan kedalam plain EXIF

4. Proses mengembalikan plain EXIF kedalam header citra digital. Sehingga posisi header citra digital kembali seperti header citra digital asli.

Dari proses analisis yang mungkin terjadi kehilangan atau perubahan data adalah di bagian proses pencarian EXIF (nomor 1) dan proses pengembalian plain EXIF setelah dilakukan dekripsi (nomor 4). Jika dilihat dari karakteristik EXIF metadata citra digital, tentunya proses tersebut dapat dilakukan tanpa kehilangan metadata aslinya. Karena dilakukan berdasarkan Tag ID. Akan tetapi, masing-masing kamera memiliki struktur cara penyimpanan EXIF metadata yang berbeda. Sebagai contoh, dalam tag "Number of bits per component" atau "BitsPerSample", memiliki panjang tipe data sebesar 3, akan tetapi 
konfigurasi kamera hanya menyimpan 2. Dalam tipe metadata EXIF tetap tersimpan 3, sedangkan setelah dekripsi akan berubah tipe metadata menjadi JFIF dan nilai yang tersimpan adalah 2, sesuai dengan panjang value terisi. Hal inilah yang terjadi di penelitian sebelumnya, terjadi kehilangan 1bit data dan menyebabkan penyusutan ukuran citra digital. Model pengidentifikasian nilai kosong dan menyamakan format EXIF Standard 2.3 dari JEIDA, dimaksudkan agar panjang nilai tidak berubah antara citra asli dan setelah dekripsi. Sehingga diperoleh nilai sama yang meminimalisasi terjadinya penyusutan ukuran file. Metode substitusi Null Value ini diterapkan pada proses sebelum proses enkripsi EXIF Metadata.

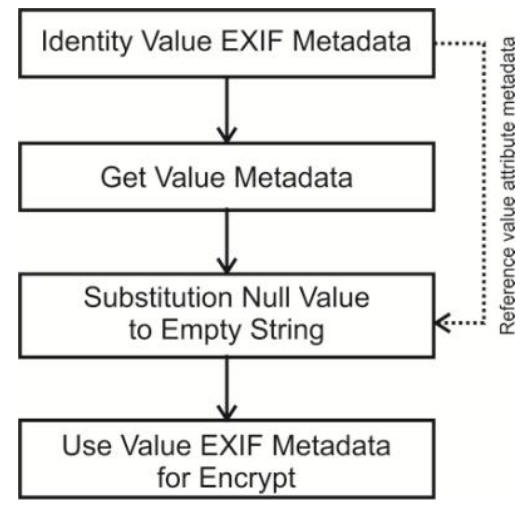

Gambar 4. Metode Substitusi Null Value

Berikut ini penerapan dengan panjang 4 bits sebagai contoh atribut yang digunakan.

1. Pada saat proses pengambilan value EXIF metadata, dilakukan analisis panjang value dan data tidak terpakai atau kosong.

2. Karena didalam tipe metadata EXIF, value kosong tetap dianggap sebagai string kosong dan bernilai 1, dan didalam proses enkripsi value kosong dianggap null, maka yang diambil untuk dienkripsi adalah value yang bernilai 1 saja.

3. Proses optimalisasi dengan cara menyertakan identifikasi nilai null yang kemudian disubstitusi dengan nilai string kosong. Sehingga value yang awalnya tidak digunakan akan bernilai 1 dengan isi string kosong.

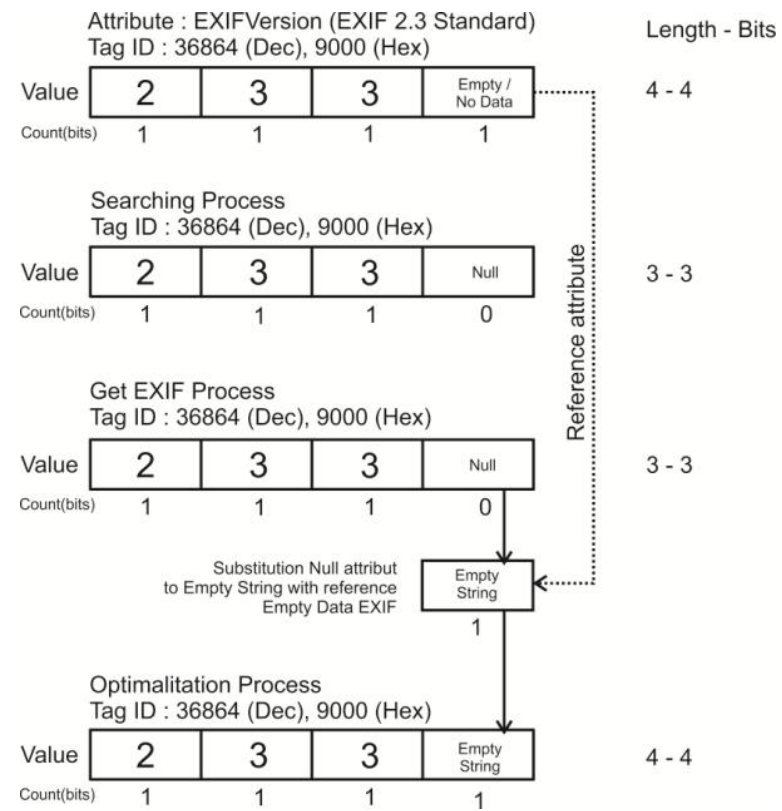

Gambar 5. Contoh Penerapan Metode Pada Atribut Metadata "EXIFVersion" 
Dari proses tersebut akan didapat nilai atribut-atribut yang sesuai dengan EXIF Standard, sehingga panjang/nilai EXIF metadata akan sama dengan panjang/nilai metadata setelah dekripsi (JFIF Metadata).

\section{HASIL DAN PEMBAHASAN}

Dalam penelitian ini menggunakan citra standard dan citra digital dari kamera Cannon EOS 450D, Cannon EOS 550D, Nikon D90, Sony DSC W110, Canno EOS 1000D, Smartphone Blackberry Z10 dan Smartphone Mi Note1 sebagai sampel citra digital. Untuk citra dari kamera digital, diambil masing-masing 5 gambar sebagai contoh dan diambil ratarata nilainya.

Untuk melakukan pengujian diperlukan analisis visual dan analisis ukuran file citra antara citra digital original dan citra digital setelah dilakukan enkripsi-dekripsi. Analisis visual digunakan untuk mengukur ada tidaknya perbedaan citra histogram, kedalaman warna dan panjang metadata. Sedangkan analisis ukuran berguna untuk membandingkan seberapa optimalkah model subtitusi ini dalam proses enkripsi-dekripsi EXIF Metadata citra digital.

\subsection{Analisis Panjang Value Metadata Citra Digital}

Tools EXIF Metadata EnDecryptor yang telah dibuat dalam penelitian sebelumnya (Wijayanto et al., 2016) memiliki struktur kode program untuk membaca seluruh EXIF untuk dijadikan bentuk string. Kemudian file citra di enkripsi dengan algoritma tertentu, yang menghasilkan EXIF citra digital terenkripsi. Potongan kode program dapat dilihat di gambar 6

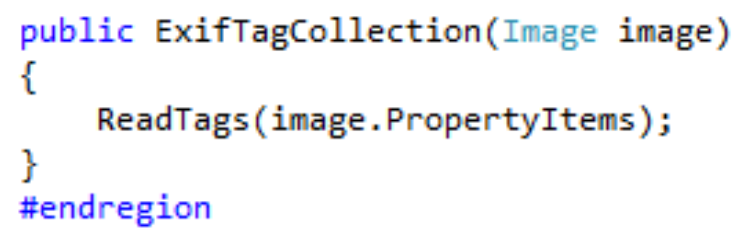

Gambar 6 Pembacaan EXIF Metadata di Tools EXIF Metadata EnDecryptor

Kode tersebut masih mengambil EXIF metadata secara menyeluruh. Modeling substitusi yaitu melakukan proses penyamaan panjang data EXIF standar dengan panjang data EXIF string. Sehingga dimaksudkan panjang pendek data EXIF metadata akan dihitung secara penuh berdasarkan Japan Electronic Industries Development Association (JEIDA). Proses ini berada saat sebelum dilakukan enkripsi, atau pada saat pembacaan metadata citra digital dengan cara mengganti string tak bernilai Null dengan space, sehingga tidak bernilai Null. Sebagai contoh implementasinya, citra digital yang diambil dengan kamera Blackberry Z0. Didalamnya terdapat komponen Camera Model "Blackberry Z10" dengan panjang 14 karakter atau 112bit. Sedangkan panjang EXIF standar JEIDA untuk Camera Model adalah 272bit (34 karakter), sehingga tersisa 160bit atau 20 karakter. Dari 20 karakter Null tersebut akan di isi dengan String kosong (atau dapat menggunakan karakter unik lain). Kondisi ini dapat di ilustrasikan seperti gambar 5. Sehingga dibutuhkan referensi dari JEIDA standar untuk mengetahui panjang bit masing-masing metadata. Untuk kode programnya seperti gambar 7 


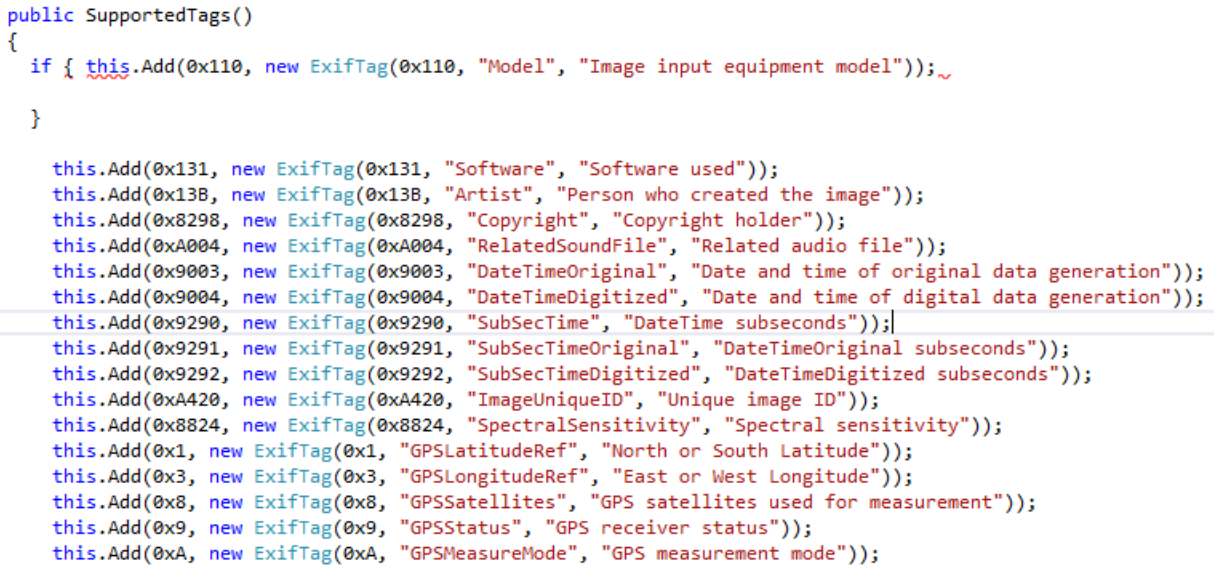

Gambar 7. Kode program referensi EXIF dari JEIDA standard

Modeling substitusi ini dapat mempengaruhi tata letak EXIF metadata di segment hexadecimal citra digital. Awalnya saat dekripsi, EXIF metadata direstore secara acak, kemudian dengan optimalisasi dapat direstore dengan memperhatikan panjang value metadata. Sehingga diperoleh struktur hexadecimal yang sama dengan citra digital aslinya (ditunjukkan pada Gambar 8).

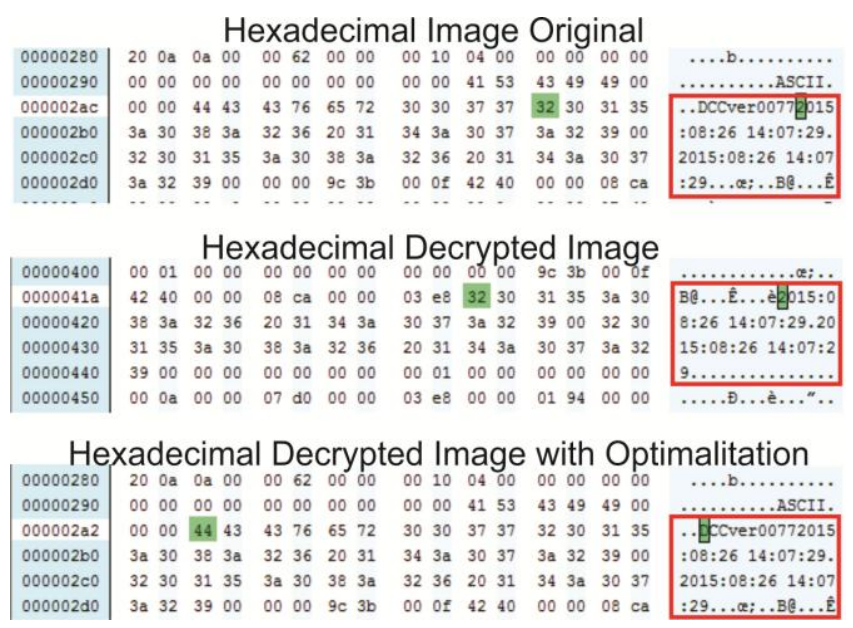

Gambar 8. Perbandingan Hexadecimal

Jika dilihat dari struktur hexadecimal tersebut menggunakan tools HexEditor, terlihat bahwa panjang EXIF metadata citra digital asli dengan setelah dilakukan dekripsi menggunakan optimalisasi, memiliki nilai yang sama. Terlihat di dalam gambar 8 posisi data hexadecimal citra digital setelah dilakukan optimalisasi berada di cluster hex 2a. Proses dekripsi tanpa optimalisasi akan mempengaruhi proses restore EXIF metadata ke header. Hal ini disebabkan value yang kosong tidak ikut dihitung sebagai nilai 1. Dengan tidak dihitungnya value yang kosong tersebut, mengakibatkan panjang metadata berubah.

Dalam proses enkripsi-dekripsi, metadata diproses dengan cara merubahnya dari bit data ke dalam plaintext. Sehingga konsistensi data akan berubah jika tidak menggunakan EXIF Standard sebagai rujukan utama.

\subsection{Tingkat Penyusutan Ukuran Citra Digital}

Dari hasil pengujian dapat ditampilkan perbandingan penyusutan ukuran seperti dalam tabel 1 berikut ini : 
Tabel 1. Perbandingan Penyusutan Citra Digital

\begin{tabular}{|l|r|r|r|r|}
\hline Image / Source & $\begin{array}{c}\text { Ukuran } \\
\text { Asli } \\
(\mathbf{K b})\end{array}$ & $\begin{array}{c}\text { Sebelum } \\
\text { Optimalisasi } \\
(\mathbf{K b})\end{array}$ & $\begin{array}{c}\text { Sesudah } \\
\text { Optimalisasi } \\
(\mathbf{K b})\end{array}$ & $\begin{array}{c}\text { Persentase } \\
\text { Penyusutan } \\
(\boldsymbol{\%})\end{array}$ \\
\hline Lenna.jpg & 54.12 & 40.79 & 53.42 & -1.30 \\
\hline Mandrill.jpg & 66.92 & 42.83 & 65.88 & -1.56 \\
\hline F1.jpg & 56.21 & 42.62 & 55.46 & -1.33 \\
\hline House.jpg & 67.98 & 53.32 & 66.91 & -1.58 \\
\hline Splash.jpg & 44.31 & 32.79 & 43.63 & -1.54 \\
\hline Tiffany.jpg & 50.53 & 38.61 & 49.69 & -1.66 \\
\hline Sailboat.jpg & 75.15 & 59.13 & 74.15 & -1.33 \\
\hline Peppers.jpg & 58.82 & 44.74 & 57.95 & -1.48 \\
\hline $\begin{array}{l}\text { Smartphone } \\
\text { Blackberry Z10 }\end{array}$ & $1,414.40$ & $1,038.69$ & 1391.43 & -1.62 \\
\hline Canon EOS 450D & $4,640.20$ & $3,504.51$ & 4559.17 & -1.75 \\
\hline Canon EOS 550D & $3,925.60$ & $2,999.46$ & 3866.05 & -1.52 \\
\hline $\begin{array}{l}\text { Canon EOS } \\
\text { 1000D }\end{array}$ & 301.80 & 236.68 & 296.77 & -1.67 \\
\hline Nikon D90 & $2,856.20$ & $2,166.39$ & 2816.33 & -1.40 \\
\hline Sony DSC W110 & $1,939.00$ & $1,457.46$ & 1910.83 & -1.45 \\
\hline Mi Note2 & $4,484.60$ & $3,091.82$ & 4417.66 & -1.49 \\
\hline \multicolumn{2}{|r|}{} & & Rata-rata & $\mathbf{- 1 . 5 1}$ \\
\hline
\end{tabular}

Melihat tabel 1 diatas, menunjukkan optimalisasi dari sisi penyusutan ukuran citra digital. Di penelitian sebelumnya menunjukkan penyusutan dengan persentase $25.15 \%$ dari ukuran aslinya. Dengan model optimalisasi substitusi Null value pada EXIF metadata ini, didapat nilai penyusutan sebesar $-1.51 \%$ dari ukuran aslinya.

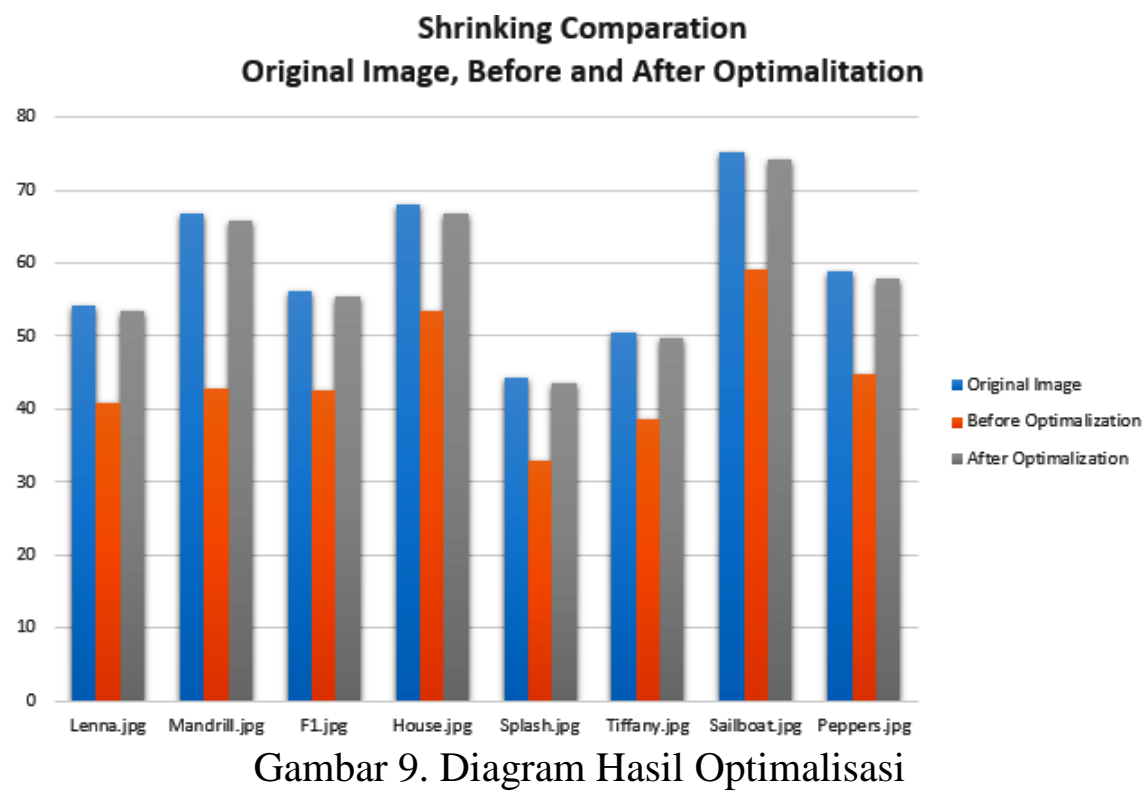

Dari gambar 9 diatas diperoleh hasil bahwa masih terdapat penyusutan ukuran citra digital. Dimana masih terdapat perbedaan tipe metadata antara citra digital asli dan citra digital setelah dilakukan pengolahan dengan software. Citra digital asli memiliki tipe metadata EXIF, dan citra digital setelah pengolahan software memiliki tipe metadata JFIF. Keduanya memiliki panjang data header yang berbeda. Hal ini nampak seperti gambar 10, dimana struktur headernya berada di posisi bit yang berbeda. Jika dilihat kluster hexadecimal, panjang header metadata JFIF berawal dari 00 sampai dengan B0, sedangkan untuk EXIF berawal dari 00 sampai dengan A0. Dengan belum 
dapat dibekukannya perubahan tipe metadata karena efek pengolahan aplikasi inilah yang menyebabkan optimalisai belum sempurna seperti ditunjukkan dalam gambar 9 .

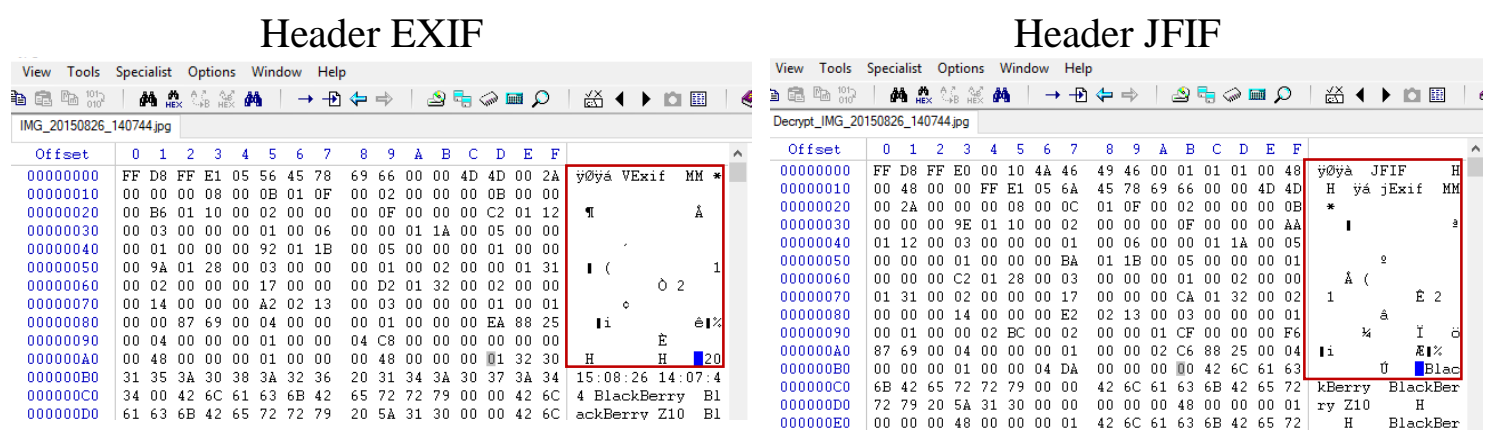

Gambar 10 Perbandingan EXIF dan JFIF

Dari hasil tersebut, perbandingan antara sebelum dan sesudah dilakukan optimalisasi, teknik substitusi ini mampu meminimalisir terjadinya penyusutan ukuran file citra digital, yang semula menyusut $-25.15 \%$ dari ukuran aslinya, menjadi $-1.51 \%$.

\section{KESIMPULAN DAN SARAN}

\subsection{Kesimpulan}

Di penelitian sebelumnya proses pengamanan EXIF metadata terjadi penyusutan $-25.15 \%$ dari ukuran aslinya. Sedangkan setelah dilakukan optimalisasi, tingkat penyusutan berubah menjadi $-1.51 \%$. Dari hasil penelitian tersebut dapat ditarik kesimpulan bahwa menyamakan panjang struktur dan nilai value antara EXIF metadata citra asli dengan PlainEXIF, dapat menghasilkan nilai yang sama juga setelah dilakukan dekripsi. Teknik substitusi null value yang dilakukan menunjukkan perubahan dengan hasil rata-rata mendekati 0 (nol). Jika nilai penyusutan mendekati 0 (nol), dapat dikatakan perubahan atau penyusutan sangat minim. Teknik substitution Null Value ini sangat bermanfaat untuk mengoptimalkan proses pengamanan hak cipta citra digital dan barang bukti digital di ranah digital forensic.

\subsection{Saran}

Penelitian ini menggunakan simulasi manual dengan tools HexEditor, EXIF Viewer dan Aplikasi penelitian sebelumnya menggunakan bahasa C\# (EXIF Metadata EnDecryptor), untuk penelitian kedepannya dapat dibuat sebuah aplikasi yang mudah dan langsung dapat digunakan. Selain itu, proses pembekuan tipe metadata EXIF agar tidak berubah menjadi JFIF ketika dilakukan pengolahan citra digital, juga dapat diteliti lebih lanjut. Dengan dapatnya dibekukan tipe metadata, maka sdapat menyempurnakan teknik pengamanan citra digital dari sisi hak cipta serta pengamanan bukti digital.

\section{DAFTAR PUSTAKA}

Casey, E. (2011). Digital Evidance And Computer Crime. Computer.

CIPA (Camera \& Imaging Product Association). (2012). CIPA DC- 008 - Translation 2012.

Huang, H. C., \& Fang, W. C. (2010). Metadata-based image watermarking for copyright protection. Simulation Modelling Practice and Theory, 18(4), 436-445. https://doi.org/10.1016/j.simpat.2009.09.004

JEIDA (Japan Electronic Industries Development Association). (2012). Metadata reference tables Standard Exif Tags. 
Ltd, N. 2000. (2000). Data Masking: What You Need to Know. A Net 2000 Ltd. White Paper, 25.

McMicken, B. (2014). Using EXIF Metadata. International Crime Scene Investigators Association, 1-20.

Raghavan, S., \& Raghavan, S. V. (2014). Eliciting file relationships using metadata based associations for digital forensics. CSI Transactions on ICT, 2(1), 49-64. https://doi.org/10.1007/s40012-014-0046-4

Sencar, H. T., \& Memon, N. (2009). Identification and recovery of JPEG files with missing fragments. Digital Investigation, 6(SUPPL.), 88-98. https://doi.org/10.1016/j.diin.2009.06.007

Wijayanto, H., Riadi, I., \& Prayudi, Y. (2016). Encryption EXIF Metadata for Protection Photographic Image of Copyright Piracy. International Journal of Research in Computer and Communication Technology, 5(5), 237-242.

Zhou, H., Shen, Y., Zhu, X., Liu, B., Fu, Z., \& Fan, N. (2016). Digital image modification detection using color information and its histograms. Forensic Science International, 266, 379-388. https://doi.org/10.1016/j.forsciint.2016.06.005 